\title{
КОГНІТИВНЕ МОДЕЛЮВАННЯ ВПЛИВУ ВЗАЄМОДІї ПОКАЗНИКІВ ПЛАНУВАННЯ ТА ВИКОНАННЯ БЮДЖЕТНОГО ПРОЦЕСУ ЗСУ НА ЕФЕКТИВНІСТЬ ОБОРОННОЇ РЕФОРМИ
}

\author{
${ }^{1}$ Василь Порохня, доктор економічних наук, професор; \\ ${ }^{2}$ Олександр Остапенко, старший викладач \\ ${ }^{1}$ Класичний приватний університет, м. Запоріжжя \\ ${ }^{2}$ Військовий інститут Київського національного університету ім. Тараса Шевченка, м. Київ
}

DOI: https://doi.org/10.31435/rsglobal_ijite/30082018/6109

\section{ARTICLE INFO}

Received 22 June 2018

Accepted 27 August 2018

Published 30 August 2018

\section{KEYWORDS}

budget program, budget risk,

cognitive model,

decision making,

defense capability reform,

Armed Forces of Ukraine.

\begin{abstract}
A significant part of the indicators of planning and implementation of the budgetary process of the Armed Forces of Ukraine (MAT) are interrelated, which affect the effectiveness of the budget policy of defense reform. Questions arise as to how to establish the properties and relationships of these links using methods of mathematical modeling.

The cognitive model of the interaction of the indicators of planning and implementation of the budget process of the Armed Forces of Ukraine on the effectiveness of defense reform in Ukraine establishes the existence of links in the management of the effectiveness of defense reform, which can be defined as critical, that is, risk-averse and provides an opportunity to assess the risk level of each contour and to model scenarios and options for improving planning and budgeting for defense reform.
\end{abstract}

Citation: Василь Порохня, Олександр Остапенко. (2018) Kohnityvne Modeliuvannia Vplyvu Vzaiemodii Pokaznykiv Planuvannia ta Vykonannia Biudzhetnoho Protsesu ZSU na Efektyvnist Oboronnoi Reformy. International Journal of Innovative Technologies in Economy. 7(19). doi: 10.31435/rsglobal_ijite/30082018/6109

Copyright: (C) 2018 Василь Порохня, Олександр Остапенко. This is an open-access article distributed under the terms of the Creative Commons Attribution License (CC BY). The use, distribution or reproduction in other forums is permitted, provided the original author(s) or licensor are credited and that the original publication in this journal is cited, in accordance with accepted academic practice. No use, distribution or reproduction is permitted which does not comply with these terms.

Вступ. Значна частина показників планування та виконання бюджетного процесу Збройних сил України (ЗСУ) пов’ язана поміж собою причино-наслідковими зв' язками, які безпосередньо або зворотно впливають на ефективність бюджетної політики оборонної реформи. Виникають питання, яким чином встановити властивості i відношення цих зв'язків, використовуючи методи математичного моделювання. Найбільш поширений із таких методів для дослідження соціальноекономічних проблем являється когнітивне моделювання, де здатність особи яка приймає рішення в цій складній функціонально-структурованій системі 3 врахуванням особливостей технології бюджетування та розвитку оборонної здатності держави є вирішальна.

В якості аналізу когнітивної моделі застосовуються механізми використання знакових $\mathrm{i}$ зважених орієнтованих графів, які вперше дослідили, як теоретично так і практично, відомі вчені: Чекленд П., Робертс Ф.С.[1] та Форрестер Дж. У.

Результати дослідження. В когнітивній моделі за допомогою орієнтованого знакового (зваженого) графа, в якому вершини відповідають елементам (підсистемам, факторам) досліджуваної системи, а дуги - взаємозв'язкам між ними, будується когнітивна карта системи. Коли вершини графа не мають ваг, то дуги зважуються знаком. При збільшенні значення фактору (вершини) і дуга призводить до збільшення значення фактору, то така дуга має позитивний знак (“+””), в протилежному випадку - негативний знак (“_”).

Відповідно теоретичного представлення граф описується кортежем когнітивної моделі[1,2,3]: 


\section{$\left(V, W i j, E, W_{E}, P r\right)$}

де $V=\left\{v_{i}\right\}$ - множина елементів системи (вершини графа);

$W i j$ - множина ваг вершин, нечітке причинно-наслідкове відношення на множині $V$;

$E-$ множина дуг;

$W_{E}=\left\{\varepsilon_{i j}\right\}-$ множина ваг дуг;

$P r-$ множина правил зміни параметрів у вершинах.

Тип контуру графа визначається як стабілізуючим або підсилюючим відхилення. В стабілізуючому контурі знакового зваженого графа кількість від’ємних зв'язків вздовж контуру непарна, а в підсилюючому контурі кількість від'ємних зв’язків вздовж контуру парна.

Цільовим фактором, як правило $\epsilon$ вершина 3 номером 1, яка має відношення 3 більшістю вершин як факторів зв'язків між факторами, які являються кількісною і якісною характеристикою досліджуваного процесу. Метою дослідження являється встановлення рівнів впливу факторів, що змінюються в часі на цільовий фактор.

На рис. 1 наведена логістична схема когнітивної моделі впливу фінансових ризиків на виконання бюджетних програм у ЗСУ.

Формування вершин, дуг графу, зв'язків між вершинами, кортежу когнітивної моделі ефективності оборонної реформи

Програми планування та

використання бюджетних ресурсів 3СУ.
Побудова орієнтованого знакового (зваженого) графа когнітивної моделі

Формування та класифікація контурів взаємодії показників планування та виконання бюджетного процесу ЗСУ

Імітаційне контурне моделювання взаємодії показників планування та виконання бюджетного процесу ЗСУ

Розробка стратегій розвитку оборонної реформи на основі контурного моделювання підсилюючих і стабілізуючих та стимулюючих і дестимулюючих сценаріїв взаємодії показників планування та виконання бюджетного процесу

\section{Рис. 1. Логістична структура когнітивної моделі}

Для дослідження впливу фінансових ризиків на виконання бюджетних програм у ЗСУ в умовах економічної нестабільності розглянемо наступний перелік факторів, які являються кількісною і якісною характеристикою досліджує мого процесу[4]:

1. ефективність оборонної реформи в Україні, направленої на підвищення військової конкурентоздатності і захист територій держави від агресора;

2. відношення спеціального фонду бюджету до загального, яке впливає на економічну та фінансову діяльність ЗСУ за видами виконання програм розбудови оборонної здатності;

3. зменшення недофінансування бюджету ЗСУ згідно 3 відомчою i програмною класифікаціями видатків та кредитування державного бюджету [5];

4. відхилення фактичних показників виконання бюджету ЗСУ згідно з відомчою i програмною класифікаціями видатків та кредитування державного бюджету;

5. зменшення відхилення планових показників бюджету ЗСУ згідно 3 відомчою i програмною класифікаціями видатків та кредитування державного бюджету від стандартів НАТО;

6. збільшення кредитних зобов'язань за програмами без значної наявності стабілізуючих фінансових ресурсів;

7. збільшення уповільнення розвитку озброєння та військової техніки ЗСУ за рахунок неефективного використання бюджетних коштів [6]; 
8. державна організаційна і фінансова підтримка, фондових структур країни, направлених на прибутковість і конкурентоздатність головних підприємств ВПК на світовому ринку [5];

9. ефективність військової допомоги держав співдружньої коаліції.

В основі когнітивного моделювання покладена можливість зменшення ризику недофінансування бюджету ЗСУ (фактор 3) та відхилення фактичних показників виконання бюджету ЗСУ(фактор 4) шляхом регулювання рівня відношення спеціального фонду бюджету до загального (фактор 1) та державної організаційної і фінансової підтримки, фондових структур країни (фактор 8), що виступають інструментами управління бюджетними і кредитними ресурсами ЗСУ.

Вище зазначене знайшло відображення у вигляді орграфу моделювання впливу взаємодії показників планування та виконання бюджетного процесу ЗСУ на ефективність оборонної реформи (рис. 2).

Когнітивна карта крім графічного зображення може бути представлена матрицею відносин або суміжності $\mathrm{C}=\left\|\mathrm{c}_{\mathrm{ij}}\right\|_{\mathrm{n} \times \mathrm{n}}$, яка $€$ реалізацією сформованого орграфу відповідно до наступної умови $[1,7]$ :

$$
\operatorname{sgn}\left(\mathrm{u}_{\mathrm{j}}, \mathrm{u}_{\mathrm{i}}\right)=\left\{\begin{array}{l}
1, \text { якщо ребро }\left(\mathrm{u}_{\mathrm{j}}, \mathrm{u}_{\mathrm{i}}\right) \text { додатне, } \\
-1, \text { якщо ребро }\left(\mathrm{u}_{\mathrm{j}}, \mathrm{u}_{\mathrm{i}}\right) \text { від'ємне, } \\
0, \text { якщо ребро }\left(\mathrm{u}_{\mathrm{j}}, \mathrm{u}_{\mathrm{i}}\right) \text { відсутнє. }
\end{array}\right.
$$

Матриця суміжності - це квадратна матриця, рядки і стовпці якої позначені вершинами графа на перетині рядків і стовпців стоять одиниці (або 0), якщо існує (немає) відношення між елементами. Їх позначення можуть мати знак "+1" або "-1".

Для оцінювання збалансованості запропонованої системи розрахують Міра відносного балансу В(К) дозволяє оцінювати збалансованість когнітивної моделі на основні визначення відношення між кількістю позитивних контурів сформованого орграфу до загальної їх кількості за умов, що $\mathrm{B}(K) \in[0 ; 1][3,7]$.

Матриця суміжності - це квадратна матриця, рядки і стовпці якої позначені вершинами графа на перетині рядків і стовпців стоять одиниці (або 0), якщо існує (немає) відношення між елементами. Їх позначення можуть мати знак "+1" або "-1".

Для оцінювання збалансованості запропонованої системи розрахують Міра відносного балансу $\mathrm{B}(\mathrm{K})$ дозволяє оцінювати збалансованість когнітивної моделі на основні визначення відношення між кількістю позитивних контурів сформованого орграфу до загальної їх кількості за умов, що $\mathrm{B}(K) \in[0 ; 1][3,7]$. Якщо отримано значення $\mathrm{B}(\mathrm{K})=1$, то орграф збалансований, а якщо отримане значення $\mathrm{B}(\mathrm{K})=0$, то незбалансований.

Міру відносного балансу В(K) визначаємо з урахуванням довжини контурів $[1,8]$ :

$$
b(K)=\frac{\sum_{k=3}^{c} \frac{1}{k} p_{k}}{\sum_{k=3}^{c} \frac{1}{k} t_{k}}
$$

де $p_{k}$-кількість позитивних циклів довжини;

$t_{k}$ - загальна кількість циклів довжини ;

$t_{k}$ - довжина найдовшого циклу в орграфі К.

Відповідно [1], динамічний аналіз нечітких величин може бути означений не тільки зв'язками, але i факторами. Для нечітких когнітивних карт використовується наступна модифікація моделі імпульсного процесу:

$$
v_{i}(t+1)=S\left(v_{i}(t)+q_{i}(t+1)+o_{i}(t+1)+\sum_{j=1}^{k} T\left(w_{i j}, p_{j}(t)\right)\right),
$$

де $v_{i}(t)$ - значення і-го фактору в момент часу $\mathrm{t}$;

$q_{i}(t+1)-$ зовнішній вплив на і-й фактор в момент часу $(\mathrm{t}+1)$;

$o_{i}(t+1)$ - керуючий вплив на i-го фактору в момент $(\mathrm{t}+1)$; 
$w_{i j}$ - інтенсивність впливу між факторами;

$p_{j}(t)$ - зміна значення в момент часу $\mathrm{t}$ (імпульс);

T - операція Т-норми;

$\mathrm{S}$ - операція S-норми (використовується S-норма Лукасевича).

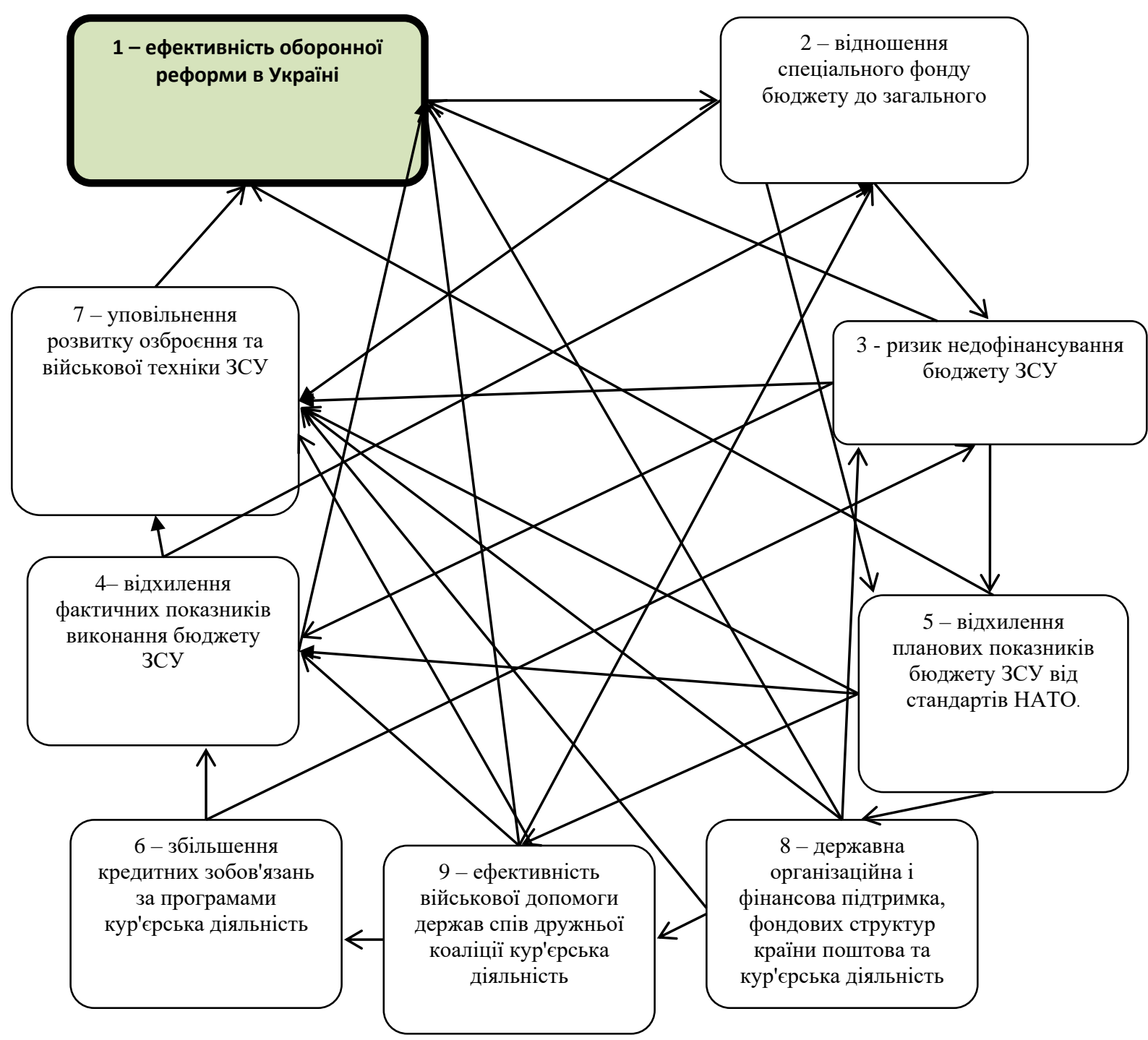

Рис. 2. Орграф когнітивної моделі впливу взаємодї показників планування та виконання бюджетного прочесу ЗСУ на ефективність оборонної реформи в Україні.

Отже, для генерації альтернатив обираються початкові значення факторів та рівень інтенсивності впливів (низький, середній, високий рівні тощо). А згенеровані альтернативи виконується для досягнення найкращого результату, де вектор впливів на керовані фактори формується на основі розроблених сценаріїв.

Матриця суміжності для орграфу представлена в табл. 1.

Орграф впливу взаємодії показників планування та виконання бюджетного процесу ЗСУ на його ефективність утворює наступні контури, наприклад:

$1 \stackrel{+}{\rightarrow} 2 \stackrel{-}{\rightarrow} 3 \stackrel{+}{\rightarrow} 5 \stackrel{-}{\rightarrow} 1$ (Ефективність оборонної реформи в Україні - Відношення спеціального фонду бюджету до загального - Ризик недофінансування бюджету ЗСУ Відхилення планових показників бюджету ЗСУ від стандартів НАТО). 
Таблиця 1. Матриця суміжності когнітивної моделі впливу взаємодії показників планування та виконання бюджетного процесу ЗСУ на його ефективність

\begin{tabular}{|c|c|c|c|c|c|c|c|c|c|}
\hline & 1 & 2 & 3 & 4 & 5 & 6 & 7 & 8 & 9 \\
\hline 1 & 0 & 1 & 1 & -1 & 1 & -1 & -1 & 1 & 1 \\
\hline 2 & 1 & 0 & 1 & -1 & 1 & 1 & 1 & 1 & 1 \\
\hline 3 & 1 & 1 & 0 & -1 & 1 & 1 & 1 & 1 & 1 \\
\hline 4 & -1 & -1 & -1 & 0 & -1 & -1 & 1 & -1 & -1 \\
\hline 5 & 1 & 1 & 1 & -1 & 0 & 1 & 1 & 1 & 1 \\
\hline 6 & -1 & 1 & 1 & -1 & 1 & 0 & 1 & -1 & -1 \\
\hline 7 & 1 & 1 & 1 & 1 & 1 & 1 & 0 & 1 & 1 \\
\hline 8 & 1 & 1 & 1 & -1 & 1 & -1 & 1 & 0 & 1 \\
\hline 9 & 1 & 1 & 1 & -1 & 1 & -1 & 1 & 1 & 0 \\
\hline
\end{tabular}

В результаті проведеного дослідження пропонується класифікація представлена в табл. 2.

Таблиця 2. Класифікація контурів за когнітивною моделлю та ефектом взаємодії

\begin{tabular}{|c|c|c|c|}
\hline \multirow[b]{2}{*}{ Види контуру } & \multicolumn{2}{|c|}{ Типи контуру } & \multirow{2}{*}{$\begin{array}{c}\text { Кількість } \\
\text { вершин }\end{array}$} \\
\hline & $\begin{array}{c}\text { За когнітивною } \\
\text { моделлю }\end{array}$ & $\begin{array}{c}\text { За ефектом } \\
\text { взаємодії }\end{array}$ & \\
\hline $1 \stackrel{+}{\rightarrow} 2 \stackrel{+}{\rightarrow} 3 \stackrel{+}{\rightarrow} 5 \stackrel{+}{\rightarrow} 1$ & стабілізуючий & стимулюючий & 4 \\
\hline $1 \stackrel{+}{\rightarrow} 2 \stackrel{+}{\rightarrow} 3 \stackrel{+}{\rightarrow} 1$ & стабілізуючий & стимулюючий & 3 \\
\hline $1 \stackrel{+}{\rightarrow} 2 \stackrel{+}{\rightarrow} 7 \stackrel{+}{\rightarrow} 1$ & стабілізуючий & стимулюючий & 3 \\
\hline $1 \stackrel{+}{\rightarrow} 2 \stackrel{+}{\rightarrow} 3 \stackrel{+}{\rightarrow} 4 \stackrel{-}{\rightarrow} 1$ & підсилюючий & дестимулюючий & 4 \\
\hline $1 \stackrel{+}{\rightarrow} 2 \stackrel{+}{\rightarrow} 3 \stackrel{+}{\rightarrow} 5 \stackrel{+}{\rightarrow} 8 \stackrel{+}{\rightarrow} 1$ & стабілізуючий & стимулюючий & 5 \\
\hline $1 \stackrel{+}{\rightarrow} 2 \stackrel{+}{\rightarrow} 3 \stackrel{+}{\rightarrow} 5 \stackrel{+}{\rightarrow} 9 \stackrel{+}{\rightarrow} 1$ & стабілізуючий & стимулюючий & 5 \\
\hline $1 \stackrel{+}{\rightarrow} 2 \stackrel{+}{\rightarrow} 3 \stackrel{+}{\rightarrow} 5 \stackrel{+}{\rightarrow} 8 \stackrel{+}{\rightarrow} 7 \stackrel{+}{\rightarrow} 1$ & стабілізуючий & стимулюючий & 6 \\
\hline $1 \stackrel{+}{\rightarrow} 2 \stackrel{+}{\rightarrow} 3 \stackrel{+}{\rightarrow} 5 \stackrel{+}{\rightarrow} 9 \stackrel{-}{\rightarrow} 4 \stackrel{-}{\rightarrow} 1$ & підсилюючий & дестимулюючий & 6 \\
\hline $1 \stackrel{+}{\rightarrow} 2 \stackrel{+}{\rightarrow} 3 \stackrel{+}{\rightarrow} 5 \stackrel{+}{\rightarrow} 8 \stackrel{-}{\rightarrow} 4 \stackrel{-}{\rightarrow} 1$ & підсилюючий & дестимулюючий & 6 \\
\hline $1 \stackrel{+}{\rightarrow} 2 \stackrel{+}{\rightarrow} 3 \stackrel{+}{\rightarrow} 5 \stackrel{+}{\rightarrow} 8 \stackrel{+}{\rightarrow} 9 \stackrel{+}{\rightarrow} 1$ & стабілізуючий & стимулюючий & 6 \\
\hline $1 \stackrel{+}{\rightarrow} 2 \stackrel{+}{\rightarrow} 3 \stackrel{+}{\rightarrow} 5 \stackrel{+}{\rightarrow} 8 \stackrel{+}{\rightarrow} 9 \stackrel{-}{\rightarrow} 4 \stackrel{-}{\rightarrow} 1$ & підсилюючий & дестимулюючий & 7 \\
\hline $1 \stackrel{+}{\rightarrow} 2 \stackrel{+}{\rightarrow} 3 \stackrel{+}{\rightarrow} 5 \stackrel{+}{\rightarrow} 8 \stackrel{+}{\rightarrow} 9 \stackrel{-}{\rightarrow} 4 \stackrel{-}{\rightarrow} 7 \stackrel{-}{\rightarrow} 1$ & підсилюючий & дестимулюючий & 8 \\
\hline $2 \stackrel{+}{\rightarrow} 3 \stackrel{+}{\rightarrow} 5 \stackrel{+}{\rightarrow} 8 \stackrel{-}{\rightarrow} 9 \stackrel{+}{\rightarrow} 2$ & стабілізуючий & стимулюючий & 5 \\
\hline $2 \stackrel{+}{\rightarrow} 3 \stackrel{+}{\rightarrow} 5 \stackrel{-}{\rightarrow} 4 \stackrel{-}{\rightarrow} 2$ & підсилюючий & дестимулюючий & 4 \\
\hline $2 \stackrel{+}{\rightarrow} 3 \stackrel{+}{\rightarrow} 5 \stackrel{+}{\rightarrow} 8 \stackrel{+}{\rightarrow} 9 \stackrel{-}{\rightarrow} 6 \stackrel{-}{\rightarrow} 4 \stackrel{-}{\rightarrow} 2$ & підсилюючий & дестимулюючий & 7 \\
\hline $3 \stackrel{+}{\rightarrow} 5 \stackrel{+}{\rightarrow} 8 \stackrel{+}{\rightarrow} 9 \stackrel{-}{\rightarrow} 6 \stackrel{+}{\rightarrow} 1$ & підсилюючий & дестимулюючий & 5 \\
\hline $1 \stackrel{+}{\rightarrow} 4 \stackrel{-}{\rightarrow} 3 \stackrel{+}{\rightarrow} 5 \stackrel{+}{\rightarrow} 8 \stackrel{+}{\rightarrow} 9 \stackrel{+}{\rightarrow} 7 \stackrel{+}{\rightarrow} 1$ & підсилюючий & дестимулюючий & 7 \\
\hline $1 \stackrel{+}{\rightarrow} 2 \stackrel{+}{\rightarrow} 3 \stackrel{+}{\rightarrow} 5 \stackrel{+}{\rightarrow} 9 \stackrel{+}{\rightarrow} 7 \stackrel{+}{\rightarrow} 1$ & стабілізуючий & дестимулюючий & 6 \\
\hline $1 \stackrel{+}{\rightarrow} 2 \stackrel{+}{\rightarrow} 3 \stackrel{+}{\rightarrow} 5 \stackrel{+}{\rightarrow} 9 \stackrel{-}{\rightarrow} 6{ }^{\rightarrow} \rightarrow 4 \stackrel{-}{\rightarrow} 7 \stackrel{-}{\rightarrow} 1$ & підсилюючий & дестимулюючий & 8 \\
\hline
\end{tabular}

Отже, 3 табл. 2 величина збалансованості графа В(К) відповідно формули, з визначенням довжини контурів має наступне значення, яке підтверджує його збалансованість 3 елементами різного впливу факторів на цільовий показник - ефективність оборонної реформи в Україні:

$$
B(K)=\frac{\frac{1}{3} \times 2+\frac{1}{4}+\frac{1}{5} \times 3+\frac{1}{6} \times 3}{\frac{1}{3} \times 2+\frac{1}{4} \times 3+\frac{1}{5} \times 4+\frac{1}{6} \times 5+\frac{1}{7} \times 3+\frac{2}{8}+\frac{1}{9}}=0,52
$$

Проаналізувавши данні 3 табл. 2 можна зробити наступні висновки, що на ступінь ризику контуру впливають такі фактори: 
- чим більше вершин входять до контуру тим вище вірогідність, що деякі з них здатні збільшувати ступінь ризикованості контуру;

- чим більше контур має зв'язків, що визначені, як критичні, тим більше він набуває властивостей контуру, що схильний до ризику.

Для прогнозування динаміки факторів 2(відношення спеціального фонду бюджету до загального, яке впливає на економічну та фінансову діяльність ЗСУ за видами виконання програм розбудови оборонної здатності), 3(зменшення недофінансування бюджету ЗСУ згідно 3 відомчою і програмною класифікаціями видатків та кредитування державного бюджету), 6 (збільшення кредитних зобов'язань за програмами без значної наявності стабілізуючих фінансових ресурсів) і 9(ефективність військової допомоги держав спів дружньої коаліції), що виступають інструментами управління бюджетними і кредитними ресурсами ЗСУ та впливу на цільову вершину 1(ефективність оборонної реформи в Україні, направленої на підвищення військової конкурентоздатності і захист територій держави від агресора). Для моделювання зазначених процесів застосуємо метод імпульсних процесів, на основі якого розроблена система підтримки прийняття рішень «Игла». Цей метод використовується для сценарного моделювання альтернатив прийняття рішень.

На рис. 3 наведена динаміка змін і впливу вершин 2 і 3 на цільову вершину 1.

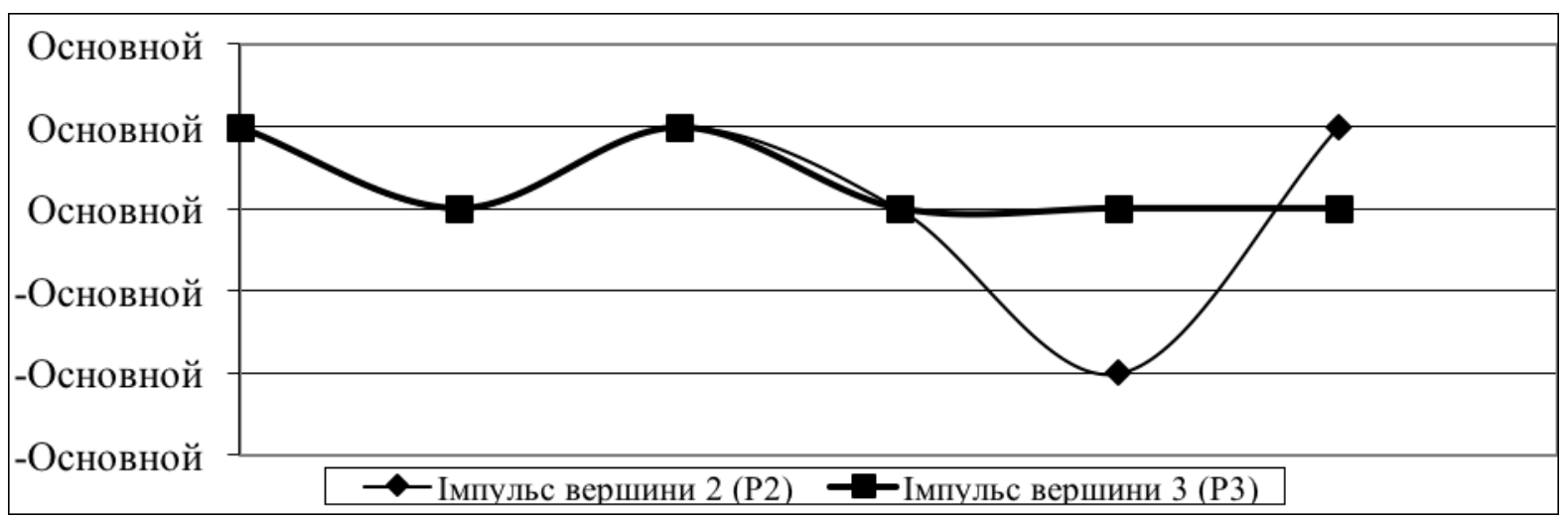

Рис. 3. Динаміка впливу імпульсів вериин 2 і 3 на ичільову вериину 1.

Зменшення недофінансування бюджету ЗСУ спочатку призводить до коливального процесу впливу на цільову вершину, але потім цей процес стабілізується. Щоду впливу вершини 2 (відношення спеціального фонду бюджету до загального) на цільову вершину то цей процес має деяку флуктацію на початку процесу, яка потім веде до позитивного підвищення цього впливу на ефективність проведення реформи ЗСУ.

На рис. 4 наведена динаміка змін і впливу вершин 6 і 9 на цільову вершину 1.

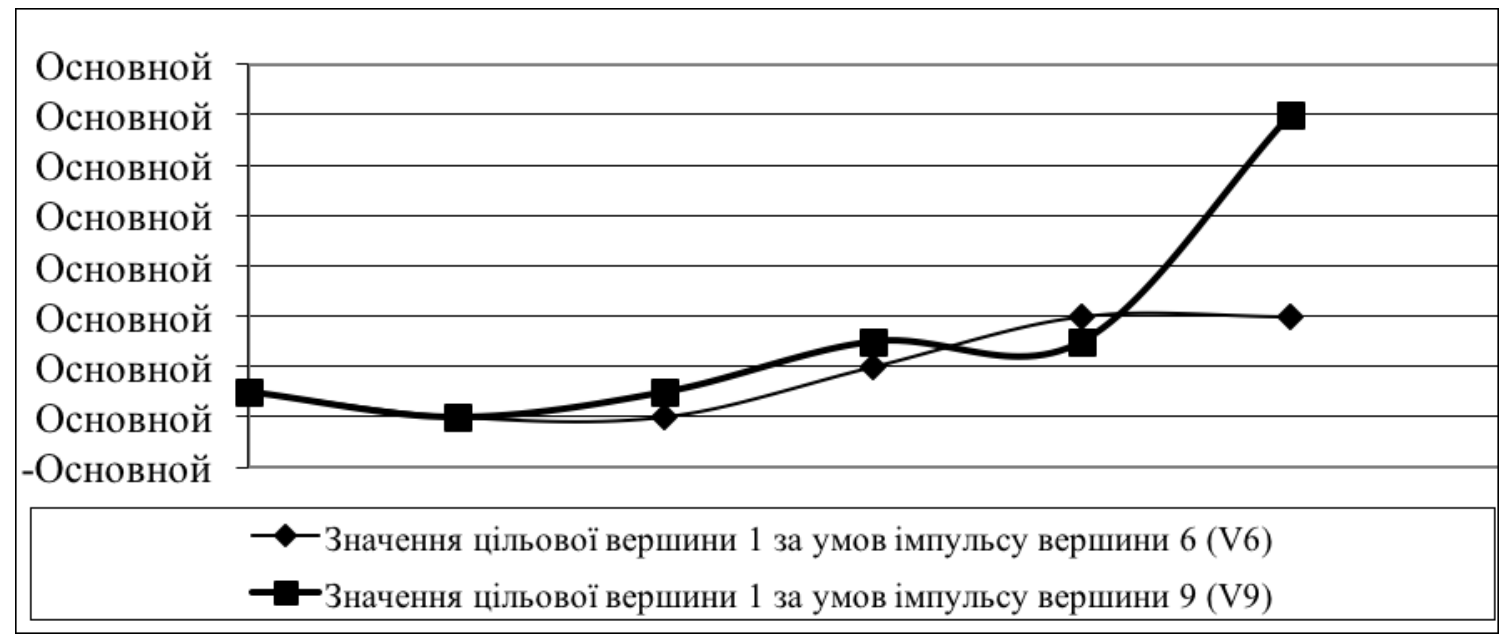

Рис. 4. Динаміка впливу імпульсів вершин 6 і 9 на ичільову вершину 1. 
Відносно впливу імпульсів вершин 6 і 9 на цільову вершину 1 має характер динамічного піднесення, але вершина 6 дещо має коливальний вигляд, що підтверджує пропорційний зв'язок ефективності реформ ЗСУ 3 ефективністю військової допомоги держав коаліції співдружності.

Висновки. Когнітивна модель впливу взаємодії показників планування та виконання бюджетного процесу ЗСУ на ефективність оборонної реформи в Україні встановлює наявність зв'язків в контурах управління ефективністю оборонної реформи, що можуть бути визначені, як критичні, тобто схильними до ризику і надає можливість оцінювання ступені ризикованості кожного контуру та моделювати сценарії і варіанти поліпшення процесів планування i використання бюджетних коштів на оборонну реформу.

\section{ЛІТЕРАТУРА}

1. Робертс Ф. С. Дискретные математические модели с приложениями к социальным, биологическим и экологическим задачам. М.: Наука, 1986. 563 с.

2. Бакурова А. В., Очеретін Д.В. Оцінка системних характеристик когнітивної моделі ціноутворення у сфері послуг. Вісник Запорізького національного університету : зб. наук. праць. 2011. № 2(10). С. $107-112$.

3. Бакурова А. В., Сергєєва Л. Н. Роль когнітивного моделювання в підвищенні ефективності вирішення економічних задач. Економічна кібернетика. 2009. № 5-6. С. 55-63.

4. Лабскер Л. Г. Общая методика конструирования критериев оптимальности решений в условиях риска и неопределенности / Л. Г. Лабскер, Е. В. Яновская // Фин. менеджмент, 2002. - № 5. - С. 58 - 74.

5. Булгакова С. Управління бюджетними ризиками / С. Булгакова, І.Микитюк // Вісник КНТЕУ. 2010. - № 2. - С. $78-88$.

6. Порохня В. М., Остапенко О. П. Оптимізаційна модель прогнозування розподілу бюджетних коштів на програми розвитку Збройних Сил України в умовах економічної нестабільності// Актуальні проблеми прогнозування розвитку економіки України : монографія. - Бердянськ, 2018. - С. 120 130.

7. Кравець О. В., Когнітивне моделювання впливу податкового регулювання на розвиток малого підприємництва в Україні. URL: http://www.economy.nayka.com.ua/?op=1\&z=5835 